\title{
Democracia Cristiana y Concertación: los Casos de Chile, Italia y Alemania
}

\author{
IGNACIO WALKER \\ Corporación de Estudios para Latinoamérica, CIEPLAN, Chile
}

\author{
ANDRÉS JOUANNET \\ Universidad Alberto Hurtado, Chile
}

\begin{abstract}
Resumen
¿Será tan sólo una coincidencia que la Democracia Cristiana -o sectores de la misma-gobierne actualmente con la izquierda socialista o socialdemócrata, en Chile, Italia y Alemania? Sin descartar tal posibilidad, especialmente en consideración a la volatilidad político-electoral de Italia, y el carácter aparentemente coyuntural de la alianza entre la Merkel y la Social Democracia en Alemania, los autores sostienen que tal vez existan razones más profundas para explicar este tipo de coaliciones, teniendo particularmente en cuenta la experiencia de la "Concertación" en Chile (1990-2010). Basados en un enfoque histórico-descriptivo, señalan que la crisis del Estado de Bienestar, en Europa, y la necesidad de un nuevo impulso en términos de crecimiento económico, competitividad e innovación, y la realidad extendida de la pobreza, la desigualdad y la exclusión, en América Latina, en el contexto más global de la post-Guerra Fría y la globalización, hacen necesario algún tipo de alianza capaz de darle un cauce de expresión política a la nueva mayoría social. Transformar la mayoría social en una mayoría política, que es lo central de la experiencia de la Concertación en Chile, bien pudiera ser la fórmula que explica la actual política de alianzas de la democracia cristiana en los tres países mencionados. El carácter más secular que religioso de la Democracia Cristiana, tanto en Europa como en América Latina, contrariamente a lo que se piensa, facilitaría este encuentro entre Democracia Cristiana y Social Democracia. Finalmente, la menor intensidad ideológica, la dinámica de la competencia electoral y la existencia de ciertas coyunturas favorables, ayudarían a explicar el surgimiento de este nuevo tipo de coaliciones políticas.
\end{abstract}

\section{Abstract}

Is it only a coincidence that presently Christian Democracy -or sectors that belonged to it- form part of political coalitions with the social democrats or socialists in Chile, Italy and Germany? Without dismissing such a possibility due to the volatility of Italian politics and the special circumstances that led to the formation of the coalition between Merkel and SPD in Germany, the authors argue that perhaps there are more profound reasons that explain these political alliances. This is especially clear in the experience of the "Concertación" in Chile (1990-2010). Based on a historic-descriptive approach, the authors argue that the crisis of the Welfare State and the need for a new impulse in terms of economic growth, competitiveness and innovation, in Europe, and the pervasive reality of poverty, inequality and exclusion, in Latin America, call for a different kind of alliances to give political expression to the social majority. Both processes should be understood within the broader context of the post Cold War period, post-authoritarianism and globalization. To transform the social majority into a political majority, which is the true meaning of the experience of the "Concertación", in Chile, could well be what explains the current political alliances of Christian Democracy in these three countries. In addition, the rather secular character of Christian democracy, in Europe and Latin America -contrary to what is usually thought- has facilitated this coming together of Christian democracy and social democracy. Finally, the diminishing ideological intensity, the dynamics of electoral competition and the existence of certain favourable and special circumstances, would help to explain the emergence of these political coalitions.

\section{PALABRAS CLAVE • Democracia Cristiana $\bullet$ Partidos políticos • Alianzas políticas • Democracia en Europa y América Latina • Política en Europa y América Latina}

Un borrador de este trabajo fue presentado, inicialmente, en un seminario organizado por Proyectamérica y CIEPLAN, el 14 de junio de 2006. Agradecemos los comentarios de Enrique Correa, Mariana Aylwin, José Antonio Viera-Gallo, Soledad Alvear y Ernesto Ottone. 


\section{INTRODUCCIÓN}

“No hay nada en común entre la Social Democracia y la Democracia Cristiana” (León XIII)ํ․ Al momento de escribir este artículo, la Democracia Cristiana (DC), o sectores que pertenecieron a ella, gobierna en coaliciones que podríamos denominar de centro-izquierda, en Chile, Italia y Alemania. Patricio Aylwin, Eduardo Frei Ruiz-Tagle, Angela Merkel y Romano Prodi son algunos de los personajes que recorren estas líneas, en alianzas políticas y electorales con representantes del mundo socialdemócrata o socialista democrático tales como Ricardo Lagos, Michelle Bachelet, Franz Müntefering y Massimo D"Alema, entre otros. La DC ha intentado distintas modalidades de coalición, en distintas realidades y épocas, aunque también ha sabido gobernar sola. En el período de la post guerra y en nuestra historia más reciente, encontramos ejemplos en uno y otro sentido.

Es así como en el caso de Chile la DC ha gobernado como partido único bajo el gobierno de Eduardo Frei Montalva (1964-1970) y luego en coalición bajo los cuatro gobiernos de la Concertación de Partidos por la Democracia (1990-2006), al interior de un esquema de centro-izquierda, ya sea bajo el liderazgo de un democratacristiano (Aylwin y Frei) o de un socialista (Lagos y Bachelet). Por otro lado, en Alemania, y en el período de la post guerra, lo hizo como partido único o en alianza con los liberales, y también, a fines de la década de 1960, bajo la “Gran Coalición”, en alianza con la Social Democracia, mientras que en la actualidad surge una nueva versión de esta última bajo el liderazgo de Angela Merkel. Por último, en Italia, durante una buena parte de la post guerra la DC gobernó sola o en alianza con los socialistas, liberales y radicales, en el contexto de una política fuertemente marcada por la necesidad de diferenciarse de la izquierda comunista, especialmente en el período de la Guerra Fría. Una excepción a este último rasgo lo constituyó el efímero acercamiento entre Aldo Moro y Enrico Berlinguer (Partido Comunista italiano), en los setenta, en pleno apogeo del "eurocomunismo" y de la amenaza terrorista de las "brigadas rojas", culminando con el secuestro y asesinato del líder democratacristiano. En el caso de la DC italiana, el fin de la Guerra Fría y el desplome del comunismo condujeron, a diferencia de los ejemplos chileno y alemán, a una fuerte fragmentación, terminando en su disolución como partido. En la actualidad, Romano Prodi, proveniente de las filas de la democracia cristiana, encabeza una coalición de gobierno de centro-izquierda (“El Olivo"), en oposición y como alternativa al gobierno de centro-derecha encabezado por Silvio Berlusconi ("La Casa de la Libertad”), que incluyó a otro sector democratacristiano.

¿Será tan sólo una coincidencia que la DC -o sectores de la misma- gobierne actualmente con la izquierda socialista o socialdemócrata, bajo distintas fórmulas y programas, en Chile, Italia y Alemania? ¿Cuáles son algunas de las características de estas experiencias de coalición política en el gobierno, en torno a lo que genéricamente pudiéramos comprender como "Concertación", tomando la expresión del caso chileno? ¿Qué tendencias se advierten en estos tres casos, en una perspectiva comparada? Son algunas de las preguntas que nos hacemos en esta reflexión.

Nuestra hipótesis, basada principalmente en un enfoque histórico-descriptivo y en el análisis de explicaciones sistemáticas y no sistemáticas, es que esta reciente convergencia es más que una 
simple coincidencia, y que, en este proceso, interviene una serie de factores explicativos; entre ellos, mencionaremos ciertas características de la globalización y la post-Guerra Fría, especialmente en el ámbito social, y la necesidad de darle un cauce de expresión política a las mayorías sociales y electorales emergentes; el reencuentro de vertientes políticas que han discurrido históricamente por cuerdas separadas (Social Democracia y DC) y que son capaces de reconstruir una forma de articulación política en torno a ciertos rasgos que tienen en común -principalmente en torno a alguna modalidad de "Estado de bienestar" o "economía social de mercado"; la menor intensidad ideológica y el abandono de cualquier atisbo de ideología marxista en la izquierda no comunista -lo que se hace aún más patente tras la caída del Muro de Berlín y el colapso de los "socialismos reales"- y, por otro lado, la consolidación de una vertiente socialcristiana que se reconcilia con la libertad, la democracia y la modernidad, al margen de todo integrismo (y como reacción contra este último); el carácter marcadamente secular de los partidos democratacristianos en Europa y en Chile, mucho más allá de lo que suele creerse o aceptarse; la dinámica de la competencia electoral y la existencia de ciertas coyunturas favorables al surgimiento de este tipo de coaliciones, son algunas de las posibles explicaciones.

Digamos, para comenzar, que, hasta ahora, los estudios comparados sobre la DC en Europa y América Latina son más bien escasos. En este sentido, entendemos el presente artículo -basado, como se ha dicho, en un enfoque histórico-descriptivo-como la base para futuras investigaciones en el campo de las coaliciones políticas en una perspectiva comparada, entre Europa y América Latina. Debemos, a decir verdad, a los trabajos de Stathis N. Kalyvas (1996) y Scott Mainwaring y Timothy R. Scully (2003) el haber contribuido, en buena medida, a llenar este vacío, tanto en Europa como en América Latina, respectivamente. Sobre la base del marco teórico y comparativo de ambos trabajos, la reflexión que se expone a continuación apunta a dar un paso más, intentando un análisis comparativo específicamente relacionado con la cuestión de las alianzas políticas entre los partidos democratacristianos de Europa (Italia y Alemania) y América Latina (Chile) -hasta ahora un campo muy poco explorado-y su relación con la social democracia o el socialismo democrático, en los tres casos señalados.

El solo hecho que este acercamiento entre DC y Social Democracia tenga lugar, en países mencionados, en la historia más reciente, es en sí mismo interesante y digno de análisis. La frase atribuida a León XIII, que encabeza este trabajo, refleja la especial sensibilidad (y distancia) que ha existido entre ambas vertientes políticas e ideológicas, desde la perspectiva católica y socialcristiana. A su vez, desde la perspectiva socialdemócrata o socialista democrática, históricamente, se ha visto en la DC una alternativa de derecha o centro-derecha (de hecho, en Chile, en la década de 1960, desde la izquierda socialista se acusó a la DC de ser "la nueva cara de la derecha").

¿Qué factores explican esta nueva realidad político-electoral, que se expresa en estas nuevas formas de coaliciones, en los tres casos bajo estudio?

En el caso chileno, es evidente que 17 años de dictadura de derecha (1973-1989), bajo la forma del capitalismo autoritario y el experimento neoliberal de los llamados "Chicago Boys", explica una buena parte de este acercamiento, bajo la forma de la Concertación. Junto con ello, sin embargo, el escenario de la globalización y la post-Guerra Fría, en un contexto postautoritario, genera nuevos "clivajes" y alineamientos, con miras a establecer una nueva mayoría política que permita reflejar los anhelos y demandas de una nueva mayoría social. 
Es a propósito de esto que se hace interesante la comparación con el caso europeo (Italia y Alemania), en que, aún con mayor solidez y consistencia, DC y Social Democracia han discurrido por cuerdas separadas. En el ejemplo chileno, plantearemos la hipótesis que, de alguna manera, la DC fue la Social Democracia que nunca existió, lo que, unido al fenómeno reciente da le renovación (socialdemocratización) de la izquierda socialista, ha encontrado un terreno fértil para el surgimiento y consolidación del fenómeno de la Concertación, la cual completará, en 2010, dos décadas en el poder.

A decir verdad, las distancias históricas que separan a la DC y la Social Democracia, en Europa, son más aparentes que reales. De alguna manera importante, la "economía social de mercado" y el "Estado de bienestar", asociados a la DC y la social democracia, respectivamente, son la base del Ilamado "modelo social" europeo. Es así como Paul Sigmund señala que "en conjunto con sus rivales socialdemócratas (los democratacristianos) crearon el moderno Estado de Bienestar europeo, financiado por un capitalismo revitalizado, que, siguiendo a Ludwig Erhard, la mente maestra detrás de la recuperación económica alemana, Ilamaron "economía social de mercado" (Mainwaring y Scully, 2003: 68). Es más. La reconciliación de Pío XII con la democracia -muy esquiva en la historia de la Iglesia Católica, habría que añadir-, las reflexiones de Juan XXIII sobre la democracia y los derechos humanos, contenidas en Pacem in Terris, y el significativo aporte del Concilio Vaticano II en torno a la "libertad religiosa" (Dignitatis Humanae), habrían creado nuevas bases para esta aproximación entre democratacristianos y social demócratas como añade Sigmund:

Comenzando en la década de 1960, hubo un claro declinar en el sello reformista e ideológico de los partidos democratacristianos europeos. Mientras que los socialdemócratas abandonaban los últimos vestigios de marxismo y los partidos de derecha aceptaban el Estado de Bienestar, las diferencias entre los partidos disminuyeron. Mientras que Europa experimentaba un proceso de creciente secularización, los elementos religiosos presente en la ideología democratacristiana llegaron a ser menos persuasivos (Mainwaring y Scully, 2003: 69).

Estos rasgos históricos se ven reforzados entre los nuevos dilemas, desafíos y exigencias que presenta el escenario de la post-Guerra Fría y la globalización, teniendo como núcleo central la "cuestión social", aunque en una nueva versión y de una manera distinta cuando se le compara con la connotación que tuvo en el período entre guerras, ligada a la doctrina social de la lglesia Católica. Ante la expansión de la democracia en lo político, y de los mercados en lo económico - los que dejan, por lo tanto, de ser criterios diferenciadores, como sí lo fueron en el pasado, en relación con la izquierda no comunista, tanto en Chile como en Europa-, tal vez lo verdaderamente característico de la actual encrucijada de Europa y América Latina sean los viejos y nuevos desafíos en el ámbito social lo que contribuya a acercar posiciones entre DC y Social Democracia. La crisis del Estado de Bienestar, en Europa y la necesidad de un nuevo impulso en términos de crecimiento económico, competitividad e innovación, y la realidad extendida de la pobreza, la desigualdad y la exclusión, en América Latina, en el contexto más amplio de la post-Guerra Fría y la globalización, hacen necesario algún tipo de alianza y de arreglo político entre las fuerzas partidarias del cambio social, capaz de darle un cauce de expresión política a la mayoría social. Transformar la mayoría social en una mayoría política, que es lo central de la experiencia de la Concertación en Chile, bien pudiera ser la fórmula que explica la actual política de alianzas de la DC en los tres países mencionados. 
En adición, este acercamiento entre ambas vertientes políticas se ha visto facilitado -en contra de lo que suele creerse o pensarse-, por el carácter marcadamente secular de los partidos democratacristianos, en Europa y en Chile. En efecto, la tesis de Stathis Kalyvas es que los partidos democratacristianos europeos, desde su etapa formativa, "son seculares más que religiosos". Aunque sus orígenes están relacionados con los conflictos entre el Estado y la Iglesia y retienen algunos trazos de identidad religiosa, "ellos están comprometidos en un discurso y práctica políticas que es, por su naturaleza, de carácter secular”. Pese a su vinculación inicial con el conflicto entre la Iglesia y los liberales, los partidos democratacristianos europeos no habrían sido un subproducto de la acción de la jerarquía de la Iglesia Católica, o de los sectores tradicionalmente más conservadores. Más bien habrían surgido "a pesar de y no, como suele pensarse, por las intenciones y acciones de la Iglesia. Ellos surgieron como producto no planificado, no deseado y en último término en detrimento de las decisiones estratégicas de la Iglesia enfrentada a serias restricciones. Tampoco fue la intención de las elites conservadoras que surgiera un partido de estas características" (Kalyvas, 1996: 1 y 18). De hecho, este desenlace -el surgimiento, en definitiva, de lo que conocemos como partidos democratacristianos europeos y las características asociadas a los mismos- habría sido una sorpresa tanto para la Iglesia como para los sectores conservadores.

Mainwaring y Scully concuerdan con Kalyvas en que efectivamente la DC, ahora referido al caso de América Latina, habría devenido en una forma bastante más secularizada, pero sin perder de vista que, en sus orígenes y en el período formativo, habrían estado estrechamente vinculados al pensamiento social de la Iglesia y la "Acción Católica”, en la terminología de Quadragesimo Anno (1931). Colocando el énfasis en la gran diversidad y heterogeneidad, ideológica y programática, de la DC en América Latina, incluso más pronunciadas que en Europa, estos partidos, desde sus inicios, habrían manifestado su autonomía en relación a la Iglesia Católica -y lo mismo habría hecho ésta respecto de aquéllos-, apareciendo incluso como partidos no confesionales y no clericales, todo lo cual habría conducido, a través del tiempo, a una cada vez más pronunciada secularización de los mismos (Mainwaring y Scully, 2003: 37 y 39).

Finalmente, son las características y dinámica de la competencia político-electoral lo que permiten la cristalización de un tipo de alianza política en un sentido u otro. El estrechísimo resultado electoral entre la Unión Demócrata Cristiana de Merkel (CDU) y el Partido Social Demócrata (SPD) de Schröeder, en Alemania, enfrentados a los cambios económico-sociales que requiere dicho país y la necesidad de asegurar una sólida mayoría política para tal efecto, y el también estrechísimo resultado electoral entre El Olivo, de Prodi, y La Casa de la Libertad, de Berlusconi, en Italia (25.000 votos de diferencia), en un esquema claramente más competitivo e inestable como el que ha conocido la república italiana en los últimos 50 años, ayudan a explicar el tipo de alianzas políticas construidas al amparo de una forma parlamentaria de gobierno. Por su parte, el sistema binominal, en Chile, bajo una forma de gobierno presidencial y un sistema multipartidista, sin duda que ha constituido un incentivo o aliciente adicional para la conformación de dos grandes bloques políticos: uno de gobierno (centro-izquierda) y otro de oposición (centro-derecha).

Estimamos que los factores mencionados anteriormente están en el centro de esta convergencia entre DC y Social Democracia. Lo anterior, sin embargo, no debe hacernos perder de vista las diferencias que existen entre los tres casos bajo estudio: el grado de desarrollo económico y 
social entre los dos casos europeos bajo estudio, y el caso chileno; la forma parlamentaria de gobierno existente en Italia y Alemania -y en Europa, en general, y la manera en que este rasgo facilita las políticas de alianzas-, sobre la base de vigorosas dinámicas regionales, frente al fuerte presidencialismo chileno, al interior de un Estado unitario; la ya larga experiencia de la Concertación, en Chile, bajo cuatro gobiernos consecutivos, frente a la muy reciente experiencia italiana y alemana -y sin perjuicio de las anteriores experiencias aliancistas a que nos referiremos en ambos casos, apoyados, en el caso alemán, por la convergencia entre la CDU y la Social Democracia a nivel de los "Lands" (25\% del total, bajo la actual Gran Coalición); unido todo ello a las diferencias ideológicas que aún subsisten entre la DC y la Social Democracia, según se expresan históricamente y en la dinámica y cambiante competencia político-electoral, son elementos que no pueden ser ignorados en el análisis y que estarán presente en la consideración de cada uno de los casos bajo estudio.

En relación a esto último, digamos que nos detendremos menos en la historia y desarrollo del caso chileno, tal vez por ser más conocido y estudiado luego de más de 15 años en el poder, y más en los casos italiano y alemán, siguiendo, en estos últimos, un enfoque "genético", que considera los factores históricos en el análisis y comprensión de los tipos de coaliciones políticas que surgen de ese desarrollo. Sólo a la luz de estos procesos históricos, a los que brevemente nos referiremos, es posible entender la verdadera naturaleza de estas políticas de alianzas.

\section{LA DEMOCRACIA CRISTIANA CHILENA}

Hay una lectura obvia con relación a la alianza entre democratacristianos y socialistas, y su común pertenencia a la Concertación de Partidos por la Democracia: 17 años de dictadura y el natural encuentro entre la DC y la izquierda en torno al tema de los derechos humanos -fundamento espiritual y ético de la Concertación-; más de veinte años de polarización y desencuentro, y las lecciones que se pueden extraer de ese trágico período de desencuentro al interior de la política chilena; las insuficiencias de la "Revolución en Libertad", con el trasfondo de la tesis del "camino propio", sin perjuicio de la enorme tarea transformadora del Presidente Frei Montalva; la natural inclinación por un esquema de centro-izquierda en un país que cuenta con una derecha más bien autoritaria en lo político -especialmente por su identificación con la reciente experiencia autoritaria-, neoliberal en lo económico y conservadora en lo cultural; el fenómeno de "renovación socialista" y los cambios al interior de la izquierda, son todos ellos factores que ayudan a explicar la natural pertenencia de la Democracia Cristiana a la Concertación.

\section{1. ¿Qué es la Concertación?}

Podría decirse que la Concertación de Partidos por la Democracia, surgida primero como Concertación por el NO, en el plebiscito convocado por la dictadura del general Pinochet en octubre de 1988, y luego como opción y coalición de gobierno, es cuatro cosas a la vez: transformar la mayoría social en mayoría política, o, dicho de otra forma, darle un cauce de expresión política a la mayoría social; propiciar una estrategia de desarrollo basada en la idea de "crecimiento con equidad (igualdad)" como una alternativa tanto al neoliberalismo como el neopopulismo; la ruptura histórica del eje socialista-comunista, que había caracterizado a la izquierda chilena desde la 
década de 1930 (Frente Popular) hasta comienzos de la década de 1970 (Unidad Popular) y, no menos importante, la convergencia entre el humanismo laico y cristiano. Es ese el significado más profundo de la Concertación de Partidos por la Democracia.

Todo lo anterior, con el trasfondo del dilema dictadura-democracia, característico de la política chilena en los últimos años y décadas. En ese contexto, la Concertación sigue apareciendo como la respuesta más sólida y coherente a ese dilema que caracterizara a Chile y América Latina al menos desde los setenta, según lo atestigua en forma invariable y por mayoría absoluta su triunfo en las catorce elecciones que han tenido lugar desde 1988 en adelante ${ }^{2}$. Se dirá que las recientes reformas constitucionales (2005) deberían ir sustituyendo ese dilema por otro, y eso es cierto, pero la subsistencia de un sistema electoral binominal -última batalla en términos de democratización política-y la falta de claridad acerca de cuál sería el nuevo "clivaje" o dilema en reemplazo del anterior, hacen que aquel, de alguna manera, se mantenga en pie. El otro dilema, aquel entre "democracia o populismo", que es el que impera en América Latina, en reemplazo del dilema entre "democracia o autoritarismo", tiene fuerza en la región, pero no en Chile, entre otras cosas, porque la Concertación ha sabido actuar como dique de contención frente a la tentación del populismo o el neopopulismo y tal vez sea esta su mayor contribución en el contexto más amplio de América Latina ${ }^{3}$.

\section{2. ¿Cuáles son, ahora, las principales resistencias o tensiones entre Democracia Cristiana y Concertación?}

La cuestión de las identidades y de cómo la DC se estaría "desperfilando" al interior de la Concertación; la percepción de que la DC estaría quedando cada vez más "sola" al interior de la misma, enfrentada al bloque PS-PPD-PRSD, cada vez más hegemónico ${ }^{4}$; la constatación de que la elección consecutiva de dos Presidentes socialistas contribuye a desplazar y marginar aún más a la DC; la falta de alternativas para un partido como la DC, en el contexto de un sistema binominal que fuerza a dos grandes coaliciones, una de gobierno y otra de oposición, una de centro-izquierda y otra de centro-derecha, en un contexto en que resulta inimaginable, al menos en el corto plazo, una alianza de la DC con la derecha; en fin, la percepción de que la DC va en retirada en el mundo de la post-Guerra Fría y de la globalización (Walker, 2000).

Ahora bien, desde un punto de vista más bien conceptual, conviene tener en cuenta algunos rasgos que ayudan a explicar esta nueva política de alianzas, contra el trasfondo de la tesis del "camino propio" de la década de 1960 y 1970.

Partamos por afirmar y recordar, en torno a esta última tesis, que ella fue planteada a fines de 1950 por el principal ideólogo de la DC, Jaime Castillo, en un contexto que poco o nada tenía que ver con la Guerra Fría o el escenario exterior, sino más bien con un elemento de política

2 Nos referimos al plebiscito de 1988, las elecciones presidenciales de 1989, 1993, 1999-2000 y 2005-2006, las elecciones parlamentarias de 1989, 1993, 1997, 2001 y 2005, y las elecciones municipales de 1992, 1996, 2000 y 2004.

3 Ver Walker (2006).

$4 \quad$ Esta idea la desarrolla, como una de sus preocupaciones, la nueva líder del PDC, Soledad Alvear, en su entrevista en el diario El Mercurio, domingo 7 de mayo de 2006. En la misma entrevista, Alvear define a la DC como un partido de "centro-izquierda". 
interna. Este último estuvo constituido por el tremendo desprestigio que habían alcanzado los partidos políticos tradicionales y que había conducido a la elección del Presidente Carlos Ibáñez (1952-1958), típica expresión de la cultura antipartidos en la política chilena del siglo XX. La tesis del "camino propio", planteada por Castillo, apuntaba básicamente a perfilar un partido de nuevo tipo, distinto de los partidos tradicionales que acusaban un gran desprestigio ante la ciudadanía. El gobierno de partido único de la DC bajo la presidencia de Frei Montalva (1964-1970), más que por la tesis del "camino propio" -aunque sería absurdo negar la existencia de un cierto mesianismo alternativista demócrata cristiano, bajo la tesis de la "tercera vía"-, en un clima de alta ideologización de la política, se explica por las características de la Guerra Fría y la extrema polarización que se desató a partir de la revolución cubana, y que condujo, en el caso chileno, a una fuerte confrontación entre las fuerzas políticas partidarias del cambio social.

En la DC chilena no existió, a decir verdad, ninguna política antialiancista en los años anteriores a la tesis del "camino propio" y desde su propia fundación como Falange Nacional, a fines de la década de 1930. Muy por el contrario, en el período que va entre 1937 y 1957, y hasta la fundación del PDC (1957), existió una fuerte propensión aliancista que se expresó desde el apoyo tácito al candidato del Frente Popular, Pedro Aguirre Cerda, en la elección presidencial de 1938 -que, de hecho, fue el argumento definitivo para la "reorganización" de la juventud conservadora y su marginación o expulsión del Partido Conservador-y en forma clara y explícita bajo los gobiernos radicales de Juan Antonio Ríos (1942-1946) y Gabriel González Videla (1946-1952).

En segundo lugar, desde esta perspectiva más conceptual, la DC chilena correspondió, de alguna manera, a la Social Democracia que nunca existió en Chile, o que sólo marginalmente existió. En efecto, una de las formas de entender tanto la fuerte implantación de la DC en la política chilena -como que ha permanecido en forma prácticamente invariable como la principal fuerza política desde 1963 hasta la fecha- y su propia aproximación posterior a la izquierda socialista, que deviene sin complejos en socialdemócrata o socialista democrática, es por ciertos rasgos que la acercan a las características comúnmente asociadas al paradigma socialdemócrata: un espacio de centro progresista, moderado y reformista, partidario del cambio social, con claro apego a la forma de la democracia representativa, en permanente competencia y como alternativa a la izquierda comunista. En cambio, al interior de la izquierda socialista chilena existió, desde sus inicios, bajo la impronta populista de Marmaduque Grove y hasta la Unidad Popular, bajo la fuerte influencia de las tesis leninistas y el influjo incandescente de la revolución cubana y la "vía armada", un permanente desprecio por el paradigma socialdemócrata. De hecho, el propio Salvador Allende era tratado despectivamente como "reformista", "socialdemócrata" o "electoralista" desde el interior de las filas de su propio partido (socialista). Fue bajo el impacto de la dictadura y a raíz del exilio de una parte importante de la izquierda socialista que esta redescubrió, por así decirlo, y pasó a valorar la socialdemocracia o el socialismo democrático europeo, hasta el punto que hay sectores en el actual Partido Socialista y el Partido por la Democracia -nacido este último como un partido "instrumental" para hacer frente a los desafíos de la transición- que consideran seriamente definirse como socialdemócratas, sin los estigmas o complejos del pasado ${ }^{5}$. La

5 Sobre la evolución histórica del Partido Socialista de Chile y el fenómeno de la "renovación socialista" al interior de la izquierda chilena, que tiene mucho que ver con el surgimiento de la Concertación de Partidos por la Democracia, ver Walker (1990). 
ausencia de esa Social Democracia facilitó la ocupación de ese espacio por un partido como el democratacristiano, que, pese a provenir de una cultura muy distinta, de raíz humanista y cristiana, cumplió de alguna manera con ese rol de una centro-izquierda moderada y reformista.

Ahora bien, este nuevo escenario, en la era de la Concertación (1990-2006), plantea nuevos desafíos y obstáculos para un partido como el demócrata cristiano. Por un lado, el fin de la Guerra Fría y el advenimiento de la globalización, junto con hacerle perder esa suerte de dramatismo que caracterizaba a la política chilena y mundial en el período de la postguerra, acaba con la "amenaza comunista" y consolida en la izquierda un nuevo socialismo democrático, típicamente representativo de la nueva izquierda chilena. Por otro lado, le plantea a la DC una seria competencia en ese mismo espacio que ha ocupado históricamente con alguna comodidad, en el sentido que, la existencia de una derecha representativa del liberalismo a ultranza -y más aún en la historia más reciente con su identificación con la dictadura de Pinochet y los Chicago Boys-y, por otro, de una izquierda marxista, dejaba todo un campo disponible para un partido como la DC. Eso ha cambiado radicalmente, lo que impone a este partido un desafío que es ineludible: cómo, a partir de su propia identidad, hacerse cargo de los nuevos desafíos de la globalización y la post-Guerra Fría, con una izquierda más "socialdemócrata" que le disputa el terreno de la centro-izquierda y del propio centro, y una derecha en busca de una nueva legitimidad que intenta acercarse al espacio del centro político, insinuando incluso la tesis del "Partido Popular" bajo la inspiración del modelo español, hasta ahora aliado de la DC.

Una de las paradojas de los dilemas y desafíos, que enfrenta la DC en esta nueva etapa y en esta nueva era, es que el propio sistema electoral binominal es el que "facilita" las cosas, dado que, en un país como Chile, con una derecha bastante sui generis, unido lo anterior a toda una historia de diferenciación de la DC con las fuerzas de la derecha -a diferencia de buena parte de la DC europea- conduce a que Ia DC se sienta más cómoda en un esquema de centro-izquierda como el de la Concertación, pero con todas las dificultades que se han señalado en esta sección en relación a las características y las nuevas posiciones ganadas por sus aliados al interior de la coalición.

Lo que es evidente es que, en la última década y media y con el trasfondo de la historia más reciente, el espacio natural para la DC ha sido el de la Concertación, como una coalición de centro-izquierda con las características que hemos descrito anteriormente.

\section{LA DEMOCRACIA CRISTIANA ITALIANA}

La DC europea, como movimiento político, se remonta a la segunda mitad del siglo XIX. Sus manifestaciones originales se encuentran en Austria (Partido Popular), Italia (Partido Popular), España (Partido Social Popular), Francia (Democrático Popular), Checoslovaquia (Partido Popular), Bélgica (Partido Católico) y Alemania (Partido de Centro). En este último país, el Zentrum Partei fue el que obtuvo mayores éxitos electorales a partir de la República de Weimar. A su vez, en Italia, el representante de esta corriente política cristiana estuvo constituido, en sus orígenes, por el Partido Popular, bajo el liderazgo de Don Sturzo. En ambos casos los partidos se enfrentaron a las líneas conservadoras de la Iglesia Católica, incluyendo una fuerte oposición al fascismo y el nazismo (Beyme, 1986: 112-113; Morsey, 1963: 237; Galato, 1955: 75). 
Tras la Segunda Guerra Mundial, los democratacristianos fueron beneficiados con el nuevo sistema político que se impone en Europa, esto es, la democracia liberal y representativa, la que termina por imponerse en Europa Occidental, bajo una no despreciable influencia estadounidense. Es así como la DC europea recoge, por una parte, los votos de la derecha, debido al desprestigio de sus partidos tradicionales a partir de su respaldo implícito o tácito a los nacional-socialismos, como también del centro, donde se encontraban los electores naturales de la DC. Sumado a lo anterior, surgen liderazgos como los de Konrad Adenauer, Alcide de Gásperi y Robert Schuman, quienes logran gravitar no sólo en el espacio de la DC, sino trascender en la común aspiración de una Europa libre, unida y democrática.

Terminada la guerra en 1946, es proclamada la República italiana. El primer gobierno de la postguerra estuvo a cargo del líder democristiano Alcide de Gásperi, quien además llevó a su partido a triunfar en los comicios parlamentarios. Luego de estas elecciones, la DC italiana pasaría a ser el partido más gravitante de la política italiana hasta principios de la década de 1990 (Giovagnoli, 1991: 1991: 163) ${ }^{6}$.

Sin embargo, la escasa estabilidad del sistema político italiano repercute en los propios partidos políticos, lo que da lugar, en el caso la DC, a fuertes fraccionamientos internos.

La DC italiana fue un partido que, hasta principios de la década de 1990, tuvo el carácter de dominante en el sistema de partidos. Sin embargo, debido a escándalos de corrupción y a sus profundas divisiones internas, el partido entra en una fase de descomposición, hasta el punto que su declinación como partido pasa a ser irreversible, conduciendo finalmente a su disolución.

Como se ha señalado, una de las principales causas de la crisis terminal que afectó a la DC italiana dice relación con su fraccionamiento interno. En este sentido, hacia principios de la década de 1970, Giovanni Sartori distingue nueve correnti, de las cuales ocho eran importantes y se dividían en proporción el espacio de poder político y económico que generaban el Gobierno y el Estado 7 .

Tal vez con la sola excepción de De Gasperi y Luigi Sturzo, en la historia de la DC nunca ha existido un líder que lograra agrupar y unificar a todo el partido. Hacia 1980, el grupo interno con mayor influencia en el partido fue el "doroteismo", el que aglutinó en su interior una serie de corrientes internas que existían al interior del partido; esta, a su vez, se transformaría en "Azione Popolare", liderado por Forlani y Andreotti.

En general, esta fragmentación interna y la supremacía de los grupos por sobre el partido llevan a la exacerbación del clientelismo de Estado, a lo que además contribuía el hecho que la DC había permanecido casi 50 años en funciones de gobierno.

Finalmente, el denominado partido "de todas las estaciones" sucumbió estrepitosamente, debido a su propio canibalismo interno y su incapacidad de poner los intereses del partido por sobre el de los grupos y los caudillos internos.

$6 \quad$ La DC italiana ha formado parte de 51 gobiernos desde que terminó la Segunda Guerra Mundial (Véase Galli, 2001).

7 Según Sartori, en el Congreso de la DC en 1971 las nueve fracciones existentes eran: a) Iniciativa Popolare 20\% (Rumor y Piccoli), b) Impegno Democratico 15\% (Colombo y Andreotti), c) Nuove Cronache 17\% (Fanfani y Forlani), d) Tavianei 10\% (Taviani), e) Morotei 13\% (Moro), f) Base 11\% (De Mita y Masasi) g) Forze Nuove 7\% (Donat y Catin), h) Forze Libere 4\% (Scalfaro), i) Nuova Sinistra 2\% (Sullo) (Sartori, 2000: 121). 


\section{Nueva Democracia Cristiana italiana: la hora de Margherita}

En las elecciones de abril de 1992, la DC y sus aliados pierden la mayoría en el parlamento, la que ostentaban desde 1946, por lo que Giulio Andreotti dimite y asume como Presidente del Gobierno el líder DC, Oscar Luigi Scalfaro, quien a su vez nombra al socialista Giuliano Amato como Primer Ministro. Sin embargo, dada la debilidad de los partidos tradicionales democratacristiano y socialista, sumado a los escándalos de corrupción que vinculan a dirigentes de estas instituciones inclusive con la Mafia y el impacto que causaría el asesinato en Sicilia del juez Giovanni Falcone, hacen que el gobierno de Amato caiga en abril de 1993. A partir de ese momento, la DC, tal como se la conocía en el período de post guerra, comenzaría lentamente a dejar de existir. Se quiebra internamente dando origen a dos líneas que se desarrollarían en el nuevo panorama político italiano, una de centro-derecha, con una escasa representación electoral, y otra de centro-izquierda, con mayor vocación electoral.

Dada la crisis de los partidos tradicionales y la desaparición de algunos de los más emblemáticos como la DC y el Partido Socialista, algunos partidos clásicos se renuevan, como el Partido Comunista italiano, que se transforma en Partido Demócrata de Izquierda y Refundación Comunista. Por su parte, la DC se desintegra en enero de 1994. El 16 de enero uno de los líderes históricos de la DC, Oscar Luigi Scalfaro, disuelve el parlamento y convoca a elecciones anticipadas, con lo que terminan cinco décadas de un sistema político y sistemas de partidos tradicionales.

En este ambiente de desafección de la política y los políticos, surge una figura que cruzará la política italiana en los últimos años, Silvio Berlusconi, magnate de los medios de comunicación. Éste formó el Partido Forza Italia, el que, aliado del líder de la Federación de la Liga Norte, Umberto Bossi, y la postfascista Alianza Nacional (AN), de Gianfranco Fini, lograron la mayoría absoluta parlamentaria en las elecciones legislativas de marzo de 1994. La coalición de Berlusconi pasaría a denominarse La Casa de la Libertad. Dada las contradicciones de esta alianza y su incapacidad de gobernar, finalmente, a siete meses de haber asumido, Berlusconi debe dimitir.

Es en este contexto que surge el Partido Popular Italiano, heredero de la DC, bajo el liderazgo de Romano Prodi. "El profesor" le llamaban a Prodi, dado su impecable currículo académico ${ }^{8}$. Este fue respaldado por los líderes más de la izquierda del Partido Popular, como Andreatta, y su amigo y mentor, Mancino. Así, en febrero de 1992 fundaron El Olivo, como una coalición de centro-izquierda que, luego de arduas negociaciones, quedó conformado por el PDS de D"Alema, el PPI de Rocco Buttiglione y la Unión Democrática de Antonio Maccanico. En las elecciones legislativas del 21 de abril de 1996, El Olivo venció por un escaso margen, con lo que Prodi asumía el $56^{\circ}$ gobierno de la República Italiana luego del fin de la guerra.

Con posterioridad a la crisis de los partidos y especialmente la experimentada por la DC italiana, este fue el primer intento de una coalición de centro-izquierda en la que los herederos directos de la DC estaban no sólo representados, sino que lideraban el proceso, a diferencia de sus primos hermanos, la "Unión de los Demócrata Cristianos de Centro", vinculada a Berlusconi y la derecha.

8 Adicionalmente, este antiguo militante democristiano había ocupado, hacia 1995 varios cargos importantes de la administración pública. Además de catedrático de economía política de la Universidad de Bolonia, fue Ministro del Tesoro (1980-1982) y de Asuntos Exteriores (1993-1994). 
Es así como en las elecciones de abril de 1996, triunfó la coalición “El Olivo", liderada por el ex democristiano Romano Prodi. Su gobierno se caracterizó por dar estabilidad política y económica, transformándose, además, en un gran protagonista de la política internacional italiana, asumiendo nada menos que la presidencia de la Unión Europea. A pesar de lo anterior, Prodi debió finalmente dimitir, debido a la pérdida de confianza por parte de uno de los socios de la coalición: Refundación Comunista. En su reemplazo, asume Massimo D"Alema, mientras que, algunos meses después, Prodi reemplazaría a Jacques Sanders en la Presidencia de la Comisión Europea. En esta elección fueron claves las gestiones hechas por la líder de la CDU alemana, Angela Merkel, quien, junto a los partidos populares europeos, teniendo la mayoría del parlamento europeo, apoyaron y promovieron la candidatura de Prodi.

Hacia fines de febrero de 1999, Romano Prodi, el ex fiscal Antonio Di Pietro y el alcalde de Roma, Franceso Rutelli, fundan un nuevo partido denominado "Los Demócratas", que ya en las elecciones europeas de ese año alcanzan un 9\% (Galli, 2001: 420-430). Tras el retorno de Berlusconi, en 2001, El Olivo comienza a ser liderado por el PDS y los ex democratacristianos, Rutelli y Prodi, quienes, agrupados en un pequeño partido al interior de esta coalición, comienzan a representar las ideas de raíz socialcristiana, al interior de una coalición de centro-izquierda. "La Margherite", como partido propiamente tal, se inaugura a partir del Congreso constitutivo realizado en Parma, en marzo de 2002, en el contexto de la nueva política en un mundo globalizado, donde la democracia y la libertad son puestas como dos pilares fundamentales de la doctrina del partido, asumiendo en esto implícitamente las raíces democratacristianas que dieron origen a la nueva República Italiana.

Como se puede observar, si bien la DC desapareció como institución burocrática de partido, ésta ha sido hoy reemplazada por el Partido Margherita, cuyos dos referentes políticos actuales más relevantes son Francesco Rutelli y Romano Prodi. Los democratacristianos progresistas italianos - llámense PPI, los Demócratas o actualmente Margherita- han tenido siempre una convicción de gobierno y de coalición de centro-izquierda, lo que además queda refrendado en su carta de principios. Lo anterior se ve confirmado en el triunfo en las recientes elecciones italianas, bajo el liderazgo de Romano Prodi, quien, junto a Rutelli, se han constituido en actores protagónicos de la política italiana y europea9.

Lo anterior demuestra que la DC sigue viva en Italia en cuanto al ejercicio del poder, pero además en cuanto a sus principios, hoy más claramente de centro-izquierda. Al decir del senador Bruno Dettori: “...hoy la DC en Italia existe en Margherita en una coalición de centroizquierda, como en Chile la DC lo anticipara en la Concertación..."10.

No podemos, pues, desconocer que, a pesar de los fraccionamientos y la crisis terminal que viviera la DC italiana, hoy esta resurge bajo una nueva modalidad en la que, a diferencia del sector de centro-derecha vinculado a Berslusconi, asume el liderazgo directo, con una figura como Romano Prodi, encabezando una coalición de centro-izquierda, muy a tono con la Concertación en Chile y la Gran Coalición que vuelve a reemerger en Alemania bajo el liderazgo de Angela Merkel. 


\section{LA DEMOCRACIA CRISTIANA ALEMANA (CDU)}

La Unión Demócrata Cristiana (CDU) es, según Klaus von Beyme (2004), el partido político más moderno de Europa. Es, además, el primer partido democratacristiano del mundo, debido a su caudal electoral y su influencia política y cultural no sólo en Alemania, sino que en toda Europa y en el mundo occidental.

Fue Konrad Adenauer quien levantó a Alemania luego de la tragedia de la Segunda Guerra Mundial, convirtiéndola en líder en Europa en materia política, social, científica y tecnológica. Adicionalmente, junto a su Ministro de Economía, Ludwig Erhard, revolucionaron la economía, poniendo en práctica el modelo de economía social de mercado, cuyo resultado concreto fue el Estado de Bienestar, al menos en una de sus vertientes.

En la primera fase, la CDU comenzó a transformarse desde un partido regionalista -como lo había sido su antecesor, el Partido de Centro- a un partido nacional y popular, con estructura burocrática, lo que le permitió enfrentar tanto los desafíos electorales, como de modernización político-social que vivía Alemania en la post guerra. En esa época, la CDU se insertaba socialmente en todos los Estados de Alemania, según la idiosincrasia que existía en cada uno de ellos. Así, por ejemplo, "este partido era socialista y radical en Berlín, clerical y conservador en Colonia, capitalista y reaccionario en Hamburgo, regionalista en München" (Schmidt, 1983: 493) ${ }^{11}$. A pesar que en esa época el partido tenía 200 mil militantes, un cuarto de los que podía exhibir la Social Democracia, la evolución hacia un partido de tipo popular y sus liderazgos internos permitieron a la Unión ser la primera fuerza política por aquellos años, cuestión que a los socialistas germanos les tomaría algunos años revertir ${ }^{12}$. Esta etapa está caracterizada además por el liderazgo sin contrapeso al interior del partido de Konrad Adenauer, quien no tiene en este periodo oposición interna.

La segunda fase de concentración del sistema de partidos (1953-1973) (Alemann, 2003: 43-62) es aquella de la competencia entre los dos partidos más importantes del sistema alemán. Al consolidarse el SPD como un partido de tipo popular y asentar su estructura territorial, junto con el importante liderazgo de Willy Brandt, comienza lentamente a competir electoralmente con la CDU.

Se destaca en este periodo la denominada Gran Coalición entre democratacristianos y socialdemócratas, constituyéndose en la primera convergencia política formal entre ambos partidos. Dada la crisis económica que enfrentó Alemania el año 1966, sumada a los problemas internos que vivía la CDU, además de los conflictos con los liberales -sus socios de coalición-, hacen que el entonces Canciller, heredero de Adenauer, Ludwig Erhard, renuncie al gobierno y en su lugar asuma el democratacristiano, Georg Kiesinger, y como vicecanciller en representación del Partido Social Demócrata (SPD), Willy Brandt. Así, ambos partidos conformaron lo que se denominó el gobierno de unidad nacional ${ }^{13}$.

11 Traducción de los autores.

12 Sólo en el "Congreso de Bad Godesberg" (1959), el SPD rompe con la tradición del partido marxista, de clase, marcando el inicio de su ascenso como partido de gobierno, asumiendo la forma de un partido de tipo "catch-all".

13 Ludwig Erhard había asumido como Canciller en reemplazo de Konrad Adenauer, quien se retirara antes que concluyera su periodo el año 1963. En las elecciones de 1965 Erhard logró para la CDU un importante triunfo electoral con un $47,6 \%$ de los votos, imponiéndose al SPD (39\%) y el FDP (9\%). 
El nuevo gobierno contaba con diez ministros de la CDU y nueve del SPD, de los cuales destacaban el ministro de economía, el socialdemócrata Karl Schiller, y el ministro de Finanzas, el socialcristiano bávaro Franz Josef Strauss. Ambos ministros llevaron nuevamente la economía alemana a una posición privilegiada. La coalición adoptó nuevos instrumentos de política económica con un importante sesgo keynesiano, a través de una reforma tributaria. Estas reformas permitieron salir de la crisis y dieron al SPD la oportunidad de mostrarse como alternativa de gobierno, lo que en definitiva consiguió el año 1969, liderando una nueva coalición con el Partido Liberal (FDP). Este último, actuando como partido bisagra, con un 5,8\% del electorado, permitió que el SPD gobernara hasta el año 1982, a pesar de haber obtenido el segundo lugar en la elección parlamentaria de ese año (Schönbohm, 1985).

Además de la coyuntura que permitió su formación, la Gran Coalición de fines de la década de 1960 presenta el interés y la particularidad de haber sido la primera oportunidad en Europa en que se configura una alianza de centro-izquierda con la participación de un partido democratacristiano, lo que sin duda constituye una innovación importante en una región en la que la DC generalmente aparece como una fuerza de centro-derecha, en competencia con la socialdemocracia. La Gran Coalición fue, desde todo punto de vista, un punto de inflexión en la política alemana, puesto que la ya consolidada democracia entraba en una fase de madurez, respeto y tolerancia por la diversidad, en la medida que las dos más importantes fuerzas políticas fueron capaces, durante tres años, de coincidir en un programa que, además de ser exitoso, demostró la viabilidad de una coalición entre los representantes de las dos fuerzas políticas más importantes en la historia reciente alemana.

A pesar de no gobernar Alemania, la CDU era la primera fuerza política alemana en el período que comentamos -salvo por las elecciones de 1972-, lo que fue facilitado por su estrategia de consolidarse como un partido con importantes liderazgos regionales. Por aquel período comienza a surgir la figura de Helmut Kohl como líder de la CDU, en su calidad de Ministro Presidente de la Región de Renania-Palatinado, pasando a constituirse en el Presidente de la CDU, en 1973.

A partir de 1976, comienza una tercera fase en la política alemana, denominada de transformación, la que duraría hasta 1990 (Alemann, 2003: 62-69). Éste es el periodo, donde la CDU pasa de partido de tipo popular a partido de tipo profesional-electoral (Beyme, 2000; Jouannet, 2004) ${ }^{14}$.

Esta etapa, fue una de modernización de la CDU, bajo el liderazgo de Helmut Kohl, quien hizo cuatro grandes transformaciones en el partido a nivel federal, las que ya había ensayado en su propia región de Renania-Palatinado, a saber: la renovación de la vieja elite del partido, la construcción de un aparato sólido fundado en una amplia base partidaria, la renovación del programa

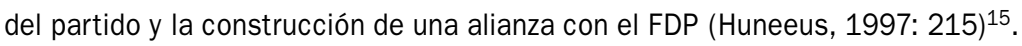

El partido profesional-electoral se caracteriza, entre otras cosas, por ser el partido de los medios de comunicación de masas, fundamentalmente la televisión. Los partidos profesionales-electorales, como lo señala su denominación, son instituciones que se preparan y viven en torno a los procesos electorales; por tanto, su accionar y sus respuestas deben responder a los hitos electorales.

15 Además de significar la modernización de la CDU como partido profesional electoral, esta fase de transformación estuvo marcada por la recuperación del poder, con una postura claramente favorable a la unificación alemana, la que contrasta con la del SPD, partido que fue contrario a esta medida por largo tiempo. 
En el otoño alemán de 1982, dadas las contradicciones políticas y económicas entre el FDP y el SPD, los liberales abandonan el gobierno dejando al Canciller Helmut Schmidt solo y en minoría en el parlamento, sin otra alternativa que renunciar a su cargo. Previamente, Helmut Kohl había negociado una coalición con los liberales, por lo que fue elegido en ese momento como Canciller de Alemania, con los votos del FDP, CDU y CSU (Unión Social Cristiana) ${ }^{16}$.

Los 16 años de gobierno de Helmut Kohl fueron de una magnitud transformadora tanto en Alemania como en Europa, con impacto en la política mundial. Esto, en el contexto de la caída del Muro de Berlín, en 1989, y la unificación alemana, los que dieron paso al fin de la Guerra Fría y posteriormente a la unificación europea. Por su parte, al interior del partido, la renovación generacional a la que hace mención Huneeus significó que Kohl promoviera a una serie de dirigentes provenientes de la Unión de Jóvenes Demócratas Cristianos y de los Universitarios Demócratas Cristianos. Entre ellos figuró Angela Merkel, proveniente de Alemania Oriental, quien fue designada como Ministra de la Mujer y que además sería electa vicepresidente del partido luego de la reunificación alemana.

La derrota de Helmut Kohl en las elecciones de septiembre de 1998, con el trasfondo de acusaciones referidas a reales o supuestos esquemas de financiamiento ilícito del partido, y el triunfo del líder socialdemócrata, Gerhard Schröeder, conducen a una crisis en la CDU, la que permitió una renovación en los cuadros dirigentes y el ascenso al liderazgo partidario de Angela Merkel. Lo anterior, a su vez, se tradujo en una renovación de los cuadros de liderazgos regionales, con lo que el partido comenzó a conquistar regiones que tradicionalmente habían estado en manos del SPD, ganando consecutivamente todas las elecciones a partir de 2002. Desde entonces, la CDU tiene la mayoría en la segunda cámara (Bundesrat), lo que contribuyó a la elección de Horst Köhler como Presidente de Alemania, dado que la CDU en ese momento gobernaba en 11 de los 16 Estados del país.

En las elecciones parlamentarias de 2002, a pesar de que la CDU junto a los socialcristianos de la CSU no lograron conformar un gobierno, debido a que el FDP resultara con menos votos que los verdes, sí pudo dar una señal de la fuerza electoral de la colectividad, la que ya venía recuperándose con un $38,5 \%$. Para las futuras elecciones regionales, la situación se hizo insostenible para el Canciller Schröeder, dado que el SPD perdió importantes bastiones históricos de los socialistas, como la Renania del Norte-Westfalia. Esto obligó al Canciller a llamar a elecciones anticipadas para el 18 de septiembre de 2005, las que tuvieron un resultado positivo para la CDU/CSU, pues obtuvo una leve mayoría sobre sus históricos rivales socialistas ${ }^{17}$.

Dado que las dos fuerzas más importantes del sistema de partidos no alcanzaron la mayoría absoluta, tanto el SPD como la CDU entendieron que debían formar un gobierno conjunto, lo que resultó en la segunda gran coalición de la historia democrática alemana. Además, debido a que de la energía atómica y mayores grados de liberalización económica, fueron algunos de los grandes temas debatidos (Alemann, 2003: 63).

17 Los resultados fueron los siguientes: Ia CDU/CSU (35,2\%), SPD (34,3\%), Verdes (8,1 \%), FDP (9,8 \%), y el Partido de Izquierda (8,7 \%). Estos resultados dieron la siguiente distribución de escaños: CDU/CSU (226), SPD (222), FDP (61), la Izquierda (53) y Los Verdes (51). 
la CDU había obtenido más votos que el SPD, éste le reconoció la posibilidad de encabezar la Bundesrepublik.

Esta segunda Gran Coalición debe ser vista con el trasfondo de las elecciones a nivel regionalestatal y a nivel municipal -sobre todo en este último nivel-, en el que se intentaron diversas modalidades de coaliciones entre la CDU y el SPD. Es en el nivel regional y local donde se ha ido cimentando una verdadera cultura de alianzas en la política alemana, la que también se ha expresado a nivel nacional, en el contexto de una forma de gobierno parlamentaria -a diferencia del caso chileno- y un sistema multipartidista, común a los tres casos bajo estudio. Así, por ejemplo, en la actualidad, de los 16 Estados que existen en Alemania, la CDU lidera 11 y el SPD cinco; de estos, la CDU gobierna sola en cinco Estados, hace coalición con el FDP en cuatro de ellos y gobierna en conjunto con el SPD en dos. Por su parte, de los Estados que lidera el SPD, en dos lo hace con el PDS, en uno con el FDP y en dos con la CDU. De esta manera, actualmente en Alemania existen cuatro gobiernos de coalición entre CDU y SPD y, en general, esta ha sido una práctica muy normal en la política regional de los dos grandes partidos en Alemania.

\section{La renovación ascendente: Angela Merkel y su liderazgo en la CDU}

El que Angela Merkel Ilegara a liderar, primero la CDU y posteriormente Alemania, no fue producto del azar ni una tarea de fácil alcance, dado que la CDU, si bien es un partido moderno de tipo profesional-electoral, tiene una estructura jerárquica patriarcal donde, hasta antes de Merkel, las decisiones eran tomadas fundamentalmente por los varones del partido, que en su mayoría eran Ministros Presidentes de las regiones donde la CDU gobernaba. Las claves en los lineamientos de Angela Merkel para la nueva CDU se pueden resumir en la reafirmación de la vigencia de los valores democratacristianos, a partir de la dignidad de la persona humana, la defensa de la familia y el derecho a la vida desde la concepción, así como la plena vigencia del modelo de economía social de mercado. Todo lo anterior debía quedar adecuadamente representado en "el nuevo centro" (Die Neue Mitte). Esta ubicación ideológica debía significar un centro incluyente, superando la vieja dicotomía de izquierda-derecha, para asumir lo que este centro considera mejor de ambas, vale decir, la igualdad y la libertad, a la vez que incorporando valores sociales y liberales dependiendo de las condiciones que la sociedad exige. Así, a la injusticia social, la respuesta era la economía social de mercado y, en relación a las libertades públicas y derechos civiles, la respuesta era una democracia de alta intensidad.

Luego de la derrota en las elecciones de 2002, Merkel adopta las decisiones políticas en la dirección de convertir a la CDU en el primer partido en las regiones, lo que le significaría la base para tener una mejor posibilidad en las elecciones del Bundestag, en 2006. Posteriormente, en el Congreso extraordinario del 11 de noviembre, en Hannover, fue reelecta por casi la unanimidad de sus miembros como Presidenta de la CDU para el período siguiente. El discurso en dicho encuentro fue en la dirección de renovar mensajes e imágenes conservadoras que se asociaban a la $\mathrm{CDU}$, sin con ello perder el sentido de lo que el partido representa en Alemania tradicionalmente (véase Wilkoszewski, 2003).

La estrategia político-electoral empezó a dar resultados, ya que la CDU comenzó a cosechar importantes victorias electorales en las regiones de Hessen y Baja Sajonia, lugares en los que el SPD tenía un control histórico. El éxito que el partido experimentaba en materia electoral 
era también debido a la recesión económica que vivía Alemania en el período de gobierno de Schröeder, dado que la crisis económica era señalada como una responsabilidad del Gobierno "Rojiverde".

La postura asumida por Merkel de reencauzar a la CDU seguía teniendo éxito, dado que, por una parte, imponía nuevas ideas en la agenda pública y, por otra, perfilaba a su partido, todo lo cual se condecía con los nuevos resultados electorales. Es así como fue reelecta presidenta del partido en el Congreso de Düsseldorf, en diciembre de 2004, culminando este proceso en las elecciones de julio de 2005, en las que la CDU/CSU obtiene una leve ventaja de votos por sobre el SPD, pero que le impide gobernar sola, o en coalición con el FDP, dada la baja votación de este último. En esas condiciones, basada en su leve mayoría sobre el SPD, la CDU, luego de intensas negociaciones, lidera el Gobierno en conjunto con los socialistas, bajo la denominada Grosse Koalition (Gran Coalición), el segundo en la historia de la Bundesrepublik. Esta unión se da en un momento en que Alemania necesita con urgencia salir de su alicaída situación económica, que desde hace varios años ha hecho que el antiguo motor económico de Europa esté paralizado, y en medio de una fuerte recesión. A lo anterior se le suma que en los últimos años los alemanes han jugado un rol secundario en materia internacional.

Fue así como el 22 de noviembre de 2005, Angela Merkel fue investida por el Bundestag como la octava Canciller de la República Alemana y la primera mujer, a la vez que la primera proveniente del Este. Respecto de la CDU, Merkel consolidó la posición de su partido en el poder parlamentario y regional, renovó su discurso y actuar, y contribuyó al surgimiento de la nueva generación que lidera actualmente a los democratacristianos alemanes.

La tarea inmediata de la alianza entre democratacristianos y socialdemócratas es sacar a Alemania de la crisis económica -como lo hiciera en 1966- y recuperar la confianza de los alemanes en la economía social de mercado y en las instituciones políticas. Puede decirse que, dados los estrechos resultados electorales y la crisis económica que cruza al país germano, fue el pueblo el que, al no otorgarle una mayoría significativa a uno sobre el otro, le señaló a ambos partidos la necesidad de que gobernaran juntos para salir de la crisis, lo que sólo se puede hacer por medio de una Gran Coalición de las dos fuerzas políticas más representativas del electorado alemán.

\section{CONCLUSIÓN}

¿Será tan sólo una coincidencia que la Democracia Cristiana -o sectores de la misma- gobiernen actualmente con la izquierda socialista, bajo distintas fórmulas y programas, en Chile, Italia y Alemania?

Lo anterior no puede descartarse. La permanente inestabilidad de la política italiana hace que distintos esquemas de gobierno se sucedan una y otra vez, algunos más hacia la centro-derecha, como bajo Berlusconi, y otros más hacia la centro-izquierda, como bajo Prodi. Las divisiones históricas y las distintas fracciones de la democracia cristiana italiana, unidas a los vaivenes de la democracia italiana, hacen que exista, desde el punto de vista de la oferta política, democracias cristianas "disponibles" -por así decirlo- en uno y otro sentido. Por su parte, la nueva Gran Coalición 
entre CDU y SPD, en Alemania, tal vez responda a una determinada coyuntura crítica que haga aconsejable una coalición como la que dirige la democratacristiana Angela Merkel (no se puede olvidar que la primera Gran Coalición de fines de los años sesenta fue de corta duración y preparó el camino para un largo período de gobierno socialdemócrata, con la DC en la oposición).

En tal sentido y en una perspectiva comparada, puede decirse que es la alianza de la Concertación, en Chile, la que presenta una mayor solidez y consistencia, en la medida que, hacia fines del actual gobierno, dicha coalición política habrá cumplido veinte años en el poder, bajo cuatro administraciones consecutivas dirigidas por dos democratacristianos (Aylwin y Frei) y dos socialistas (Lagos y Bachelet). Sin duda que el escenario "postautoritario" y la historia reciente de desencuentros y polarización han contribuido a ello.

¿Podrá entonces hablarse de un nuevo modelo de coalición de centro-izquierda, el modelo de la Concertación?

En respuesta a esta última pregunta puede sugerirse la hipótesis de que la aproximación de la DC chilena a la izquierda "renovada" (socialdemócrata o socialista democrática) y la reconciliación de esta última con sus congéneres europeos, todo esto según emerge de nuestra historia más reciente, nos habla de una nueva síntesis, en la forma de una coalición política, entre paradigmas que han discurrido por cuerda separada (DC y Social Democracia, en Chile y Europa), en torno a lo que se conoce como Concertación. Tal vez sea ésta, en un esquema de centro-izquierda, en el escenario de la post-Guerra Fría y en la era de la globalización, con el trasfondo de una política postautoritaria, como en el caso chileno, la que mejor exprese la realidad actual de la DC en Chile, Italia y Alemania.

En este sentido, hemos sugerido la hipótesis de que es más que una simple coincidencia que estas alianzas políticas surjan en la historia más reciente. Aunque el eje derecha-izquierda nunca ha sido cómodo para los partidos democratacristianos - "más allá de derechas e izquierdas" fue la consigna del PDC chileno en su período de formación como colectividad política-, tal vez sea este esquema de centro-izquierda el que más se aviene con las características de un partido "nacional y popular", según la vieja definición de la DC chilena, que bien se puede aplicar a los casos de Italia y Alemania, bajo la fórmula del "bloque por los cambios" que intentaran, en alguna oportunidad, el eurocomunismo y Berlinguer.

Esta síntesis de acuerdos entre democratacristianos y socialdemócratas o socialistas democráticos, que se inicia en 1966 con la Gran Coalición alemana, continúa con la Concertación chilena (1990-2006) y, más recientemente, con El Olivo italiano y la nueva versión de la Gran Coalición, son el resultado, en el caso europeo, de la evolución de la izquierda hacia el socialismo liberal, y en el caso chileno de la "socialdemocratización" de la izquierda. Por su parte, la DC, tanto en Europa como en Chile y sin perjuicio de las diferencias entre ellas, asume un ideario libertario-progresista -con distintos grados de intensidad, variando de un caso a otro-, que permite una natural convergencia con esta nueva izquierda. Adicionalmente, en el caso de Europa, la convergencia reciente entre socialdemocracia y democracia cristiana se ve facilitada, especialmente desde la perspectiva de la Unión Europea, por temas de la política internacional que son muy sensibles a los valores que históricamente representan ambas vertientes políticas, como la democracia, los derechos humanos, la paz y la seguridad. 
Es aún prematuro prever o predecir lo que ocurrirá en Alemania e Italia, aunque es más predecible y fácil de prever lo que ocurrirá en Chile, al menos mientras perduren los últimos vestigios del "clivaje" autoritarismo-democracia que explica, además del sistema electoral y factores de la cultura política chilena, la realidad de los orígenes y desarrollo de la Concertación. Es esta última, sin embargo, la que pareciera explicar muchas de las características en materia de políticas de alianzas de la Democracia Cristiana en la realidad actual de Chile, Italia y Alemania.

\section{REFERENCIAS}

Alemann, Ulrich. 2003. Das Parteiensystem der Bundesrepublik Deutschland. Bonn: Ediciones Central für Politische Bildung.

Baker, Kendall, Russell Dalton y Kai Hildebrandt. 1981. Germany Transformed: Political Culture and the New Politics. Cambridge: Harvard University Press.

Beyme, Klaus von. 1986. Los partidos políticos en las democracias occidentales. Madrid: Ediciones Siglo XXI.

Beyme, Klaus von. 2000. Parteien im Wandel. Von den Volksparteien zu den Professionalisierten Wählerparteien. Wiesbaden: Ediciones Westdeutscher.

Beyme, Klaus von. 2000a. Die politischen Theorien der Gegenwart. Wiesbaden: Ediciones Westdeutscher.

Beyme, Klaus von. 2004. Das politische System der Bundesrepublik Deutschland. Wiesbaden: Ediciones Westdeutscher. Bobbio, Norberto. 1999. Destra e sinistra. Ragioni e significati di una distinzione politica. Roma: Ediciones Donzelli.

Caciagli, Mario. 1991. “¿Condenada a gobernar? La Democracia Cristiana en el sistema político italiano”. Working Paper $\mathrm{N}^{\circ} 41$, Universidad de Barcelona.

Dunleavy, Patric. 1980. “The Urban Basis of Political Alignment”. British Journal of Political Science 9: 409-444.

Erhard, Ludwig. 1988. Gedanken aus fünf Jahrzehnten. Reden und Schriften. Düsseldorf, Wien, New York: Edición Karl Hohmann, Economía.

Fleet, Michael. 1985. The Rise and Fall of Chilean Christian Democracy. Princeton, New Jersey: Princeton University Press.

Franklin, Marck. 1985. The Decline of Class Voting in Britain. Oxford: University Press Oxford.

Galato, Vittorio. 1955. Storia Della Democrazia Cristiana. Roma: Ediciones Donzelli.

Galli, Giorgio. 2001. I Partiti Politici Italiani 1943-2000. Milano: Ediciones Rozzolli.

Giddens, Anthony. 1994. Beyond Left and Right. The Future of Radical Politics. Cambridge: Polity Press Cambridge/ Cornwall.

Giovagnoli, Agnelli. 1991. La cultura democristiana. Roma-Bari: Ediciones Laterza.

Granato, Mona y Karin Schittenhelm. 2004. “Junge Frauen: Bessere Schulabschlüsse - aber weniger Chancen beim Übergang in die Berufsausbildung”. Aus Politik und Zeitgeschichte 28.

Huneeus, Carlos. 1997. "La modernización de un partido político: La CDU de Alemania Federal y el liderazgo de Helmut Kohl". Estudios Públicos 68: 215-251.

Inglehart, Ronald. 1996. Modernization and Postmodernization, Cultural, Economic, and Political Change in 43 Societies. Princeton, New Jersey: Princeton University Press.

Jouannet, Andres. 2004. Politische Parteien in Lateinamerika Strukturen und Innenleben im Kontext der marktwirtschaftlichen Reformen. Heidelberg: Ediciones Universidad de Heidelberg.

Kalyvas, Stathis. 1996. The Rise of Christian Democracy in Europe. Ithaca y Londres: Cornell University Press.

Lynch, Edward. 1993. Latin America"s Christian Democratic Parties: a Political Economy. Westport Connecticut: Praeger.

Lipset, Seymur Martin, Terry Clark y Michael Rempel. 1993. "The Declining Political Significance of Social Class". International Sociology 8: 293-316.

Mainwaring, Scott y Timothy Scully. 2003. Christian Democracy in Latin America. Stanford-California: Stanford University Press.

Margherita. 2002. Carta de Principi. La Margherita-Democrazia è Libertà. Congresso Costitutivo 22-24 marzo 2002, Fiera di Parma.

Mayeur, Jean Marie. 1988. Partidos Católicos y Democristianos Europeos. En Diccionario de Política. Suplemento, editado por Norberto Bobbio, Nicola Matteucci y Gianfranco Pasquino. México: Ediciones Siglo XX.

Morsey, Rudolf. 1963. Die Deutsche Zentrumspartei 1917-1923. Düsseldorf: Ediciones Droste.

Pasquino, Gianfranco. 1979. “Italian Christian Democracy: A Party for all Seasons?” West European Politics 3: 88-109.

Sartori, Giovanni. 2000. Partidos y sistemas de partidos. Madrid: Ediciones Alianza. 
Schmidt, Ute. 1983. “Die Christlich Demokratische Union Deutschlands”. En Die Parteien in der Bundesrepublik Deutschland 1945-1980. Parteien-Handbuch (tomo 1), editado por Stöss Richard. Opladen: Ediciones Schriften des Zentralinstituts für sozialwissenschaftliche Forschung der Freien Universität Berlin, 490-660.

Schönbohm, Wulf. 1985. Die CDU Word moderne Volkspartei. Selbstverständnis, Mitglieder, Organization und Apparat 1950-1980. Stuttgart: Ediciones Klett-Cotta.

Scully, Timothy. 1992. Los partidos de centro y la evolución política chilena. Santiago: Cieplan-Notre Dame.

Walker Ignacio. 1990: Socialismo y democracia: Chile y Europa en perspectiva comparada. Cieplan-Hachette, Santiago. Walker, Ignacio. 2000. El futuro de la democracia Cristiana. Santiago: Grupo Zeta Ediciones.

Walker, Ignacio. 2004. "The Future of Chilean Christian Democracy". En Christian Democracy in Latin America, editado por Scott Mainwaring y Timothy Scully. California: Stanford University Press, 162-195.

Walker, Ignacio. 2006. "Democracia en América Latina”. Foreign Affairs 6 (2): 3-24.

Wilkoszewski, Harald. 2003. Die verdrängte Generation. Politische Parteien und die alternde Gesellschaft in Deutschland. München: Ediciones Tectun.

Ignacio Walker es Doctor (Ph. D.) en Ciencias Políticas de la Universidad de Princeton, Estados Unidos. Además, es Abogado y Licenciado en Ciencias Jurídicas y Sociales de la Universidad de Chile. Ex Ministro de Relaciones Exteriores (2004-2006) y ex Diputado de la República (1994-2002) es en la actualidad Presidente de la Corporación de Estudios para Latinoamérica, CIEPLAN.

(E-mail: iwalker@cieplan.cl)

Andrés Jouannet es Doctor (Ph. D.) en Ciencias Políticas de la Universidad de Heidelberg, Alemania, y Magíster en Ciencias Políticas de la Universidad de Chile. Es Profesor de Ciencias Políticas en la Universidad Alberto Hurtado y Asesor del Ministerio Secretaría General de la Presidencia.

(E-mail: ajouannetv@yahoo.com) 